\title{
Dispersibility of Kaolinite-Rich Coal Gangue in Rubber Matrix and the Mechanical Properties and Thermal Stability of the Composites
}

\author{
Kenan Zhang ${ }^{1}$, Hao Zhang ${ }^{2}$, Linsong Liu ${ }^{1}$, Yongjie Yang ${ }^{1}$, Lihui Liu ${ }^{1}$ and Qinfu Liu ${ }^{1, *}$ \\ 1 School of Geoscience and Survey Engineering, China University of Mining and Technology (Beijing), \\ Beijing 100083, China; zhangkenan2019@126.com (K.Z.); linsong3260@163.com (L.L.); \\ Jason.yang885@outlook.com (Y.Y.); liulihui1993@126.com (L.L.) \\ 2 School of Chemical and Environmental Engineering, China University of Mining and Technology (Beijing), \\ Beijing 100083, China; zhh199175@outlook.com \\ * Correspondence: lqf@cumtb.edu.cn
}

check for updates

Citation: Zhang, K.; Zhang, H.; Liu, L.; Yang, Y.; Liu, L.; Liu, Q. Dispersibility of Kaolinite-Rich Coal Gangue in Rubber Matrix and the Mechanical Properties and Thermal Stability of the Composites. Minerals 2021, 11, 1388. https://doi.org/ $10.3390 / \min 11121388$

Academic Editors: Qi Tao, Hongfei Cheng and Manuel Pozo Rodríguez

Received: 28 October 2021

Accepted: 6 December 2021

Published: 8 December 2021

Publisher's Note: MDPI stays neutral with regard to jurisdictional claims in published maps and institutional affiliations.

Copyright: (c) 2021 by the authors. Licensee MDPI, Basel, Switzerland. This article is an open access article distributed under the terms and conditions of the Creative Commons Attribution (CC BY) license (https:/ / creativecommons.org/licenses/by/ $4.0 /)$.

\begin{abstract}
The aim of this work was to investigate the dispersibility of kaolinite-rich coal gangue in rubber matrix, the mechanical properties and thermal stability of coal gangue/styrene butadiene rubber (SBR) composites, and to compare these properties to those of the same coal gangue but had undergone thermal activation and modification. Several experimental techniques, such as X-ray diffraction (XRD), X-ray fluorescence (XRF), scanning electron microscopy (SEM), Fourier-transform infrared spectroscopy (FTIR), thermogravimetric-differential scanning calorimetry (TG-DSC), laserscattering particle analyzer were adopted to characterize the coal gangue particles and then the obtained composites. The results demonstrated the raw coal gangue (RCG) was mainly composed of kaolinite. Calcination led to amorphization of thermal activated coal gangue (ACG), increased hydrophilicity and void volume, and decreased $\mathrm{pH}$. The grain size of ACG became coarser than RCG, but ACG turned loose confirmed by higher degree of refinement after grinding. Modification enhanced the hydrophobicity of the coal gangue and improved its dispersibility than fillers without modification. Calcined samples had better dispersibility than uncalcined fillers. Additionally, the coal gangue treated by calcinating, grinding and modifying (MGA) had the best dispersion in rubber matrix. Either calcination or modification could improve the mechanical properties and thermal stability of coal gangue filled rubber, while the performance of MGA reinforced SBR (MGA-SBR) was the best. The enhanced performance of the MGA-SBR was owed to better dispersion of particles as well as stronger interactions between particles and rubber macromolecules.
\end{abstract}

Keywords: calcination; modification; dispersion; reinforcement; SBR; composite

\section{Introduction}

Nowadays, coal gangue has been the largest industrial solid wastes in China with the accumulative amount of exceeding 5 billion tons and an annual stockpile increasing at a rate of 0.3 billion tons [1,2]. Massive amount of coal gangue is not properly utilized, resulting in waste of resources, as well as waste disposal and environmental problems $[3,4]$. As a secondary resource, coal gangue has the potential to be used as polymer filler [5-7]. Coal gangue is composed of inorganic and organic components with some unsaturated points and polar functional groups, including hydroxyl and carboxyl groups, etc., locate on. Organic composition in coal gangue may augment the inter-attraction of this particle and the matrix [5]. The volatile components act as softeners, and the sulfur can prevent reversion during curing process. The fixed carbon components after ultrafine crushing show superior reinforcing performance. Consequently, coal gangue shows different properties when used as rubber filler relative to carbon black or white carbon black (silica). At present, the activation methods of coal gangue mainly include mechanical activation, chemical activation, thermal activation, microwave activation, and composite activation [8-11]. 
Most of the coal gangue in the Late Paleozoic strata of North China is rich in kaolinite [12]. Kaolinite is a naturally occurring clay mineral with a layer structure comprised of siloxane and gibbsite-like layers $[13,14]$. Grinding can reduce the particle size and increase the specific surface area of the kaolinite within a proper grinding time. More importantly, grinding may produce structural alterations of the kaolinite resulting in disorder and degradation of the crystal structure $[15,16]$. The kaolinite after grinding may behave differently. Thermal activation is a common means of achieving high chemical reactivity of coal series kaolinite prior to further applications [17,18]. Calcinated kaolinite or metakaolinite is widely used because of its relatively simple chemical composition and high reactivity [19]. Calcination caused the original kaolinite crystal structure collapsed, and converts crystalline kaolinite in coal gangue to disordered, metastable metakaolinite through anion imbalance caused by dehydroxylation and rearrangement of $\mathrm{Si}$ and $\mathrm{Al}$ atoms [20-22]. Kaolinite could be used as functional filler for rubber based on its light color, special layered structure, and availability [20]. Kaolinite can increase mechanical properties of the filled rubber system, enhance its gas barrier property and thermal stability, and decrease its flammability [2,20,23-26]. The application of kaolinite in the preparation of organomodified fillers for rubber has also been reported [27,28]. Kaolinite is able to replace silica in the specific rubber products, and is suitable to reinforce more steric rigid rubber [29]. The high aspect ratio of kaolinite enables the filled rubber system to have good thermal and gas resistance [24]. The notably improved thermal stability of kaolinite/rubber composites than precipitated silica filled rubber can be attributed to the special shape and arrangement of kaolinite in the rubber matrix [20]. Researchers [20,23,30] suggested that kaolinite improved the thermal stability of rubber by diluting the number of combustible materials, blocking the heat flow, and preventing the mass flow.

The general performance of elastomers is significantly affected by the dispersion state and aggregate size of filler in the rubber matrix [24,31], and the bond of the filler-rubber [32]. After thermal activation, kaolinite-rich coal gangue would undergo various changes, such as the destruction of lamellar structure, the changes of particle size and surface properties, and the pre-removal of organic components, all of which may affect the performance of the composite. Although the application of clay minerals in rubber substrate is an old and ongoing research topic [33-36], few works have been completed so far to study the compositional and structural changes of thermal activated and modified kaolinite-rich coal gangue and the performance of the filled rubber system including mechanical and thermal stability.

In this work, the properties influencing the dispersibility of coal gangue and its calcined counterpart were studied in comparison. The two starting coal gangue were grinded and modified before applied to SBR, the most widely used rubber [32], based on the simple melt mixing method. The performance of coal gangue reinforced SBR were analyzed to determine the effect of thermal activation and modification on the mechanical properties and thermal stability of the composites. The results may help to alleviate the accumulation of coal gangue and promote the utilization of kaolinite-rich coal gangue in the field of functional filler.

\section{Materials and Methods}

\subsection{Materials}

Raw kaolinite-rich coal gangue (RCG) was collected from Pingshuo Mine in the Shanxi province of China. The chemical composition of RCG determined by XRF is shown in Table 1. Four rubber fillers were prepared by thermal activating, grinding and modifying the coal gangue. SBR1502 was manufactured by China Petroleum Fushun Petrochemical Company (Fushun, China). The water-soluble organic modifier with amine groups was prepared by our laboratory. Rubber additives including zinc oxide, stearic acid, accelerator NS (N-tert-butylbenzothiazole-2-sulphenamide), and sulfur were all commercially available in China and were used as purchased. 
Table 1. Chemical composition (wt. \%) of raw kaolinite-rich coal gangue (RCG).

\begin{tabular}{cccccccccccc}
\hline Oxide (wt. \%) & $\mathrm{SiO}_{\mathbf{2}}$ & $\mathrm{Al}_{\mathbf{2}} \mathbf{O}_{\mathbf{3}}$ & $\mathrm{Fe}_{\mathbf{2}} \mathbf{O}_{\mathbf{3}}$ & $\mathrm{TiO}_{\mathbf{2}}$ & $\mathbf{C a O}$ & $\mathbf{N a}_{\mathbf{2}} \mathbf{O}$ & $\mathbf{K}_{\mathbf{2}} \mathbf{O}$ & $\mathbf{M n O}$ & $\mathbf{M g O}$ & $\mathbf{P}_{\mathbf{2}} \mathrm{O}_{\mathbf{5}}$ & Ignition Loss \\
\hline Coal gangue & 43.16 & 37.63 & 0.429 & 1.39 & 0.230 & 0.072 & 0.129 & 0.005 & 0.174 & 0.074 & $16.62^{1}$ \\
\hline \multicolumn{1}{c}{${ }^{1}$ LOI: Loss on ignition at $900{ }^{\circ} \mathrm{C}}$.
\end{tabular}

\subsection{Sample Preparation}

The activated coal gangue (ACG) was obtained by calcining the raw coal gangue (RCG) at $800{ }^{\circ} \mathrm{C}$ for $60 \mathrm{~min}$ in an electric furnace. The starting coal gangue (RCG or ACG) was wet ground for one $\mathrm{h}$ in a sand mill (CNB-1L) at $2000 \mathrm{r} / \mathrm{min}$ with a solid content of $20 \%$. Then, the slurry was diluted to the solid content of $10 \%$. Superfine coal gangue powder (GR or GA) was prepared by spray drying the diluted slurry. On the other hand, the modifier with a mass of $1 \%$ of coal gangue was slowly dropped into diluted slurry. Then, the slurry was stirred for $1 \mathrm{~h}$ and spray-dried to obtain modified sample (MGR or MGA).

The formulations of the coal gangue filled SBR (phr) are shown in Table 2. The solid SBR was plasticized through an internal mixer (XK-160 type) and then mixed with coal gangue, zinc oxide, stearic acid, NS, and sulfur to form the plasticized compound. The optimum curing time $\left(t_{90}\right)$ of the compound was measured by a moving die rheometer (MDR-2000E). Finally, the coal gangue/SBR composite was molded using a flat electric heating vulcanizer (XLB-50T2) for the optimum curing time. The composites filled with GR, GA, MGR, and MGA were named as GR-SBR, GA-SBR, MGR-SBR, and MGA-SBR, respectively.

Table 2. Formulation of the coal gangue reinforced SBR.

\begin{tabular}{ccccccc}
\hline Ingredient & SBR & Zinc Oxide & Stearic Acid & Accelerant (NS) & Sulphur & Fillers \\
\hline Content $/ \mathrm{phr}^{1}$ & 100.00 & 3.00 & 1.00 & 1.00 & 1.75 & 50.00 \\
\hline
\end{tabular}

${ }_{1}^{1}$ phr is the abbreviation of parts per hundreds of rubber.

\subsection{Characterization}

The chemical composition of the coal gangue (RCG) was measured using X-ray fluorescence analysis (XRF; AxiosmAX, Malvern Panalytical, Almelo, Netherlands) according to China national standard GB/T 14506.28-2010. The loss on ignition of RCG was determined by weight method.

The determination of OAN is based on the Chinese national standard of GB/T 3780.2-2007 method $\mathrm{B}$. The $\mathrm{pH}$ of coal gangue was measured in accordance with Chinese national standard of GB/T14563-2008.

The mineral phases of starting coal gangue (RCG and ACG) were identified by X-ray diffractometer (Rigaku D/max 2500 PC, Tokyo, Japan) with $\mathrm{Cu} \mathrm{K} \alpha$ radiation of $0.1540596 \mathrm{~nm}$ operated at $40 \mathrm{kV}$ and $100 \mathrm{~mA}$. Samples were scanned using continuous sweep method in the $2 \theta$ range of 2.5 to $70^{\circ}$ at a scanning speed of $2^{\circ} / \mathrm{min}$. The sampling width was $0.02^{\circ}$ during scanning. Slit system: $\mathrm{DS}=\mathrm{SS}=1^{\circ}, \mathrm{RS}=0.3 \mathrm{~mm}$.

The contact angle was determined with contact angle measurement (JY-82B Kruss DSA, Hamburg, Germany) with water as the test medium. The average value of sample's left and right contact angles was used to evaluate the hydrophobicity of the sample.

The particle size distribution of coal gangue before and after grinding was measured with laser particle size analyzer (Malvin Mastersizer 2000, Malvern Panalytical, Malvern, UK). Test conditions: water as dispersion medium, cycle injection, test 1-2 min. Each sample was tested five times and the average of the results was used to characterize the sample's size range.

The starting coal gangue and liquid nitrogen brittle section of reinforced rubber were observed with scanning electron microscope (SEM; Hitachi SU8020, Tokyo, Japan) at accelerating voltages of 20.0 and $5.0 \mathrm{kV}$, respectively, to compare the morphology of coal gangue and their dispersion in the rubber matrix.

The Fourier transform infrared (FTIR) patterns of coal gangue samples between 4000 and $400 \mathrm{~cm}^{-1}$ were recorded using a Nicolet 6700 Fourier infrared spectrometer 
(Thermofisher, Waltham, MA, USA) at a resolution of $4 \mathrm{~cm}^{-1}$ in $\mathrm{KBr}$ pellet form (2 mg sample in $300 \mathrm{mg} \mathrm{KBr}$ ).

The Mooney viscosity was determined by $\left(\mathrm{MV}_{2}-2000\right.$, China) in accordance with the national testing standard of China (GB/T 1233-2008). The $t_{90}$ and mechanical properties of coal gangue/SBR composites were measured according to respective Chinese national standards (GB/T 16584-1996, GB/T 531.1-2008, GB/T 528-2009, GB 529-2008). For each data of hardness, three different sites on the sample were measured and the average value was taken. For each data of tensile property, five parallel measurements were carried out and the average value was taken. Additionally, for each data of tear property, four parallel measurements were carried out.

The thermal analysis of raw coal gangue (RCG), as well as thermal stability of coal gangue reinforced SBR were studied with thermogravimetric analyzer (Mettler-Toledo, Greifensee, Switzerland). About $10 \mathrm{mg}$ of each sample underwent thermal analysis. Both tests were in a nitrogen environment with a heating rate of $10^{\circ} \mathrm{C}$ per min. However, the temperature range of the former test was 30 to $1100{ }^{\circ} \mathrm{C}$ and the latter test 30 to $800{ }^{\circ} \mathrm{C}$.

\section{Results and Discussion}

3.1. Characterization of Starting Samples and Fillers

3.1.1. Composition and Structure of Starting Samples

Most peaks in the X-ray diffraction pattern of RCG (Figure 1) can be attributed to kaolinite, except for two weak peaks labeled by the solid downward triangle and solid diamond, which represent boehmite and negligible quartz, correspondingly. The molar ratio of $\mathrm{SiO}_{2}$ to $\mathrm{Al}_{2} \mathrm{O}_{3}$ in $\mathrm{RCG}$ is 1.95 (Table 1), which is close to the theoretical ratio of kaolinite and indicates that kaolinite is the main mineral component. Approximately, the content of kaolinite, boehmite and organic matter in coal gangue is $92.8 \%, 4.2 \%$, and $3.0 \%$ (wt $\%$ ), respectively, based on XRD and XRF results. After calcination, all peaks of kaolinite vanished and a diffuse band located between 15 and $30^{\circ}$ appeared in the pattern of ACG (Figure 1), indicating the conversion of kaolinite in coal gangue to amorphous metakaolinite [37]. It was reported that this conversion was essentially based on the coordination of $\mathrm{Al}$ element from hexavalent aluminum $\left(\mathrm{Al}^{\mathrm{VI}}\right)$ to hexavalent aluminum $\left(\mathrm{Al}^{\mathrm{VI}}\right)$, pentavalent aluminum $\left(\mathrm{Al}^{\mathrm{V}}\right)$ and tetravalent aluminum $\left(\mathrm{Al}^{\mathrm{IV}}\right)$ [38-40]. The peak of boehmite disappeared because it decomposed at about $400{ }^{\circ} \mathrm{C}$. The peak of quartz became obvious, probably caused by better dissociation of quartz under thermal stress. Titania bearing phase cannot be identified easily in original clay when present in small quantity [41]. Kaolinite underwent amorphization due to calcination, allowing the characteristic peak of anatase overlapping with kaolinite at $d=0.35 \mathrm{~nm}$ to surface.

Thermal activation resulted in dehydroxylation of kaolinite-rich coal gangue, which was justified by the TG-DSC analysis of RCG presented in Figure 2. The weight losses in the temperature intervals of $30-105^{\circ} \mathrm{C}, 105-475{ }^{\circ} \mathrm{C}$, and $475-980{ }^{\circ} \mathrm{C}$ in TG curves were $1.2 \%, 3.0 \%$, and $13.0 \%$, respectively, representing desorption of water, decarbonization, and dihydroxylation of RCG [41,42]. The dehydroxylation of kaolinite resulted in the formation of metakaolinite. The evident endothermic peak at $528{ }^{\circ} \mathrm{C}$, the weak exothermic peak at $894^{\circ} \mathrm{C}$ and a strong exothermic peak at $1001^{\circ} \mathrm{C}$, representing the dehydroxylation of kaolinite, the transformation of $\gamma-\mathrm{Al}_{2} \mathrm{O}_{3}$ to $\theta-\mathrm{Al}_{2} \mathrm{O}_{3}$ and the formation of Al-Si spinel, respectively $[13,21,43-45]$. Of note, the similar thermal decomposition behavior of RCG relative to kaolinite in previous research $[42,46]$ also indicated that the main mineralogical component of RCG was kaolinite. 


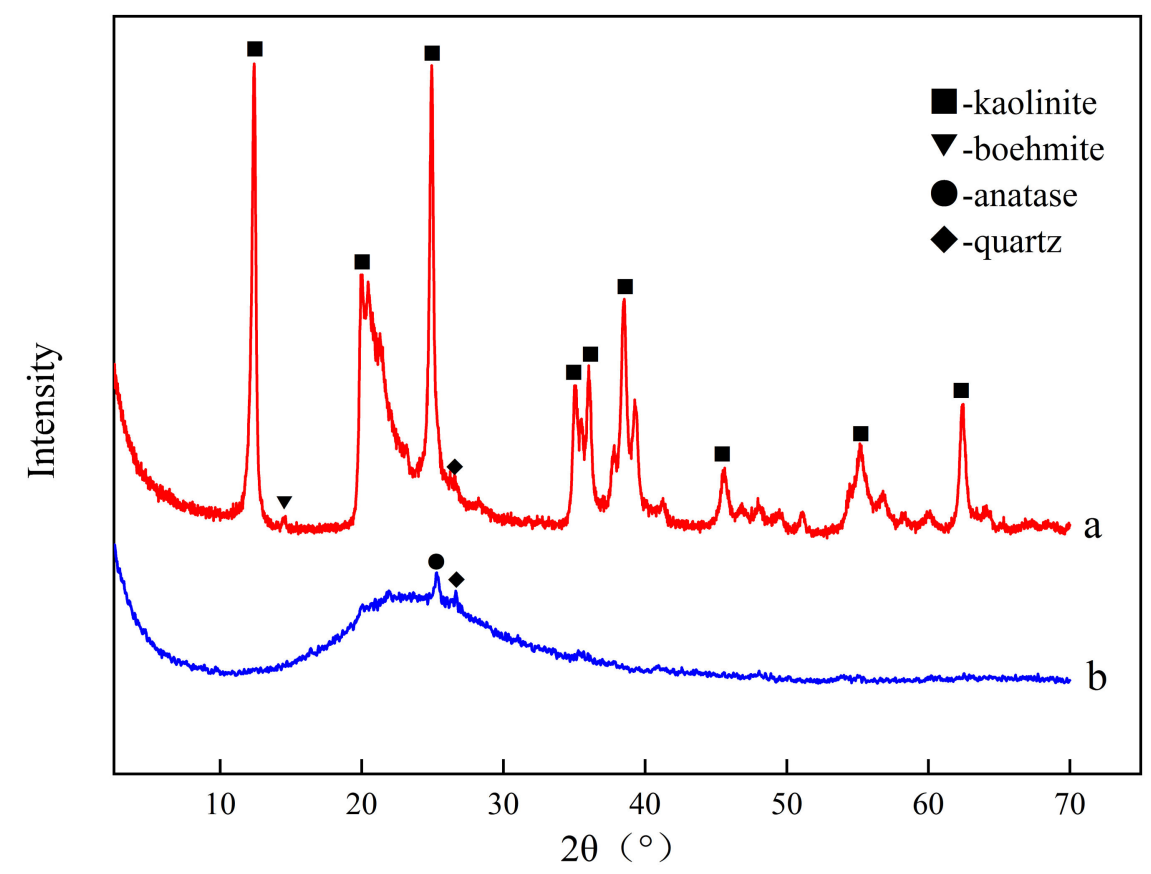

Figure 1. XRD patterns of starting samples: (a) RCG; (b) ACG.

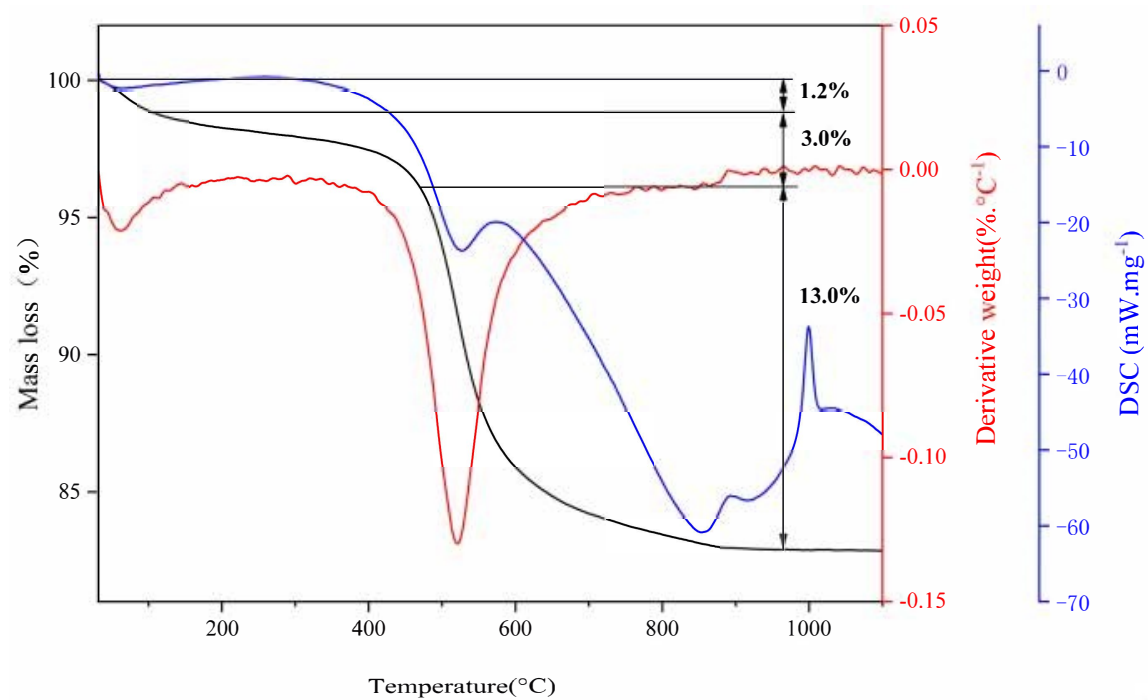

Figure 2. TG-DTG-DSC curves of RCG.

As shown in Figure 3, RCG was mainly in the plate-like structure, with small sheets attached to large layers of well-crystallized kaolinite. The kaolinite layers collapsed and broke into small ones after calcining, which effectively increased inter-particle void space, meanwhile some particles agglomerated. The void volume increase in coal gangue was also proved by the oil absorption number (OAN). The OAN of ACG was $80 \mathrm{~cm}^{3} / 100 \mathrm{~g}$, much larger than $39 \mathrm{~cm}^{3} / 100 \mathrm{~g}$ of RCG, indicating that thermal activation increased the inter-particle space of coal gangue and no apparent void closure caused by sintering. 


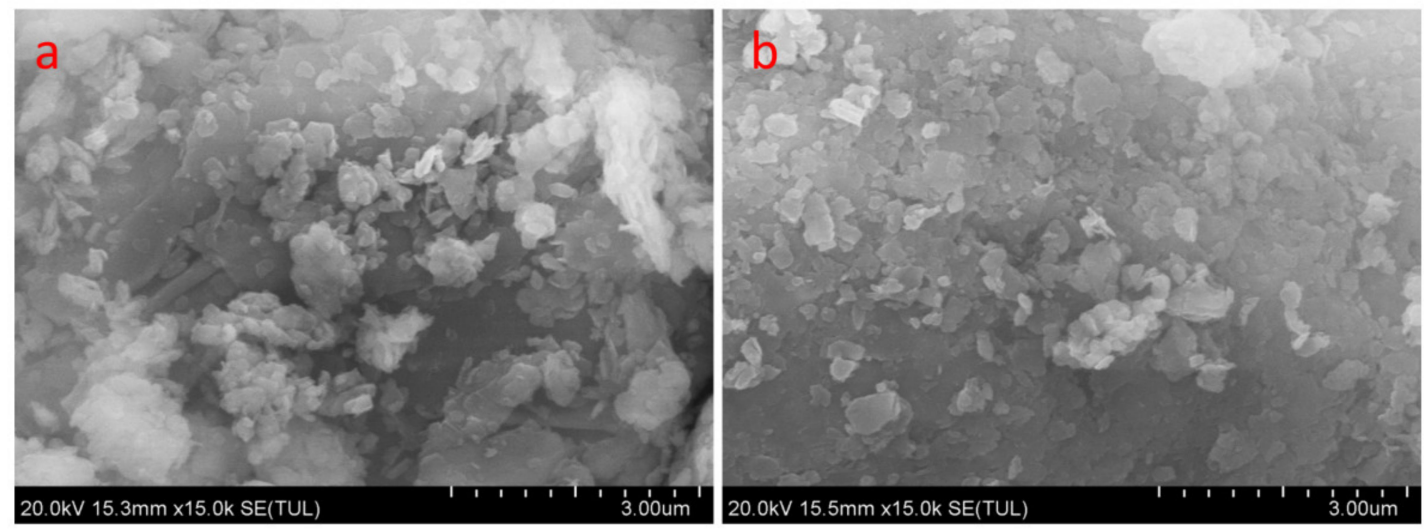

Figure 3. SEM micrographs of starting sample: (a) RCG; (b) ACG.

\subsubsection{Particles Size of Starting Samples before and after Grinding}

Coarse grain inorganic particles cannot be used as reinforcing filler for rubbers and only after ultra-fine refinement can they show the reinforcing effect. Ultra-fine pulverization increases the contact area between the particles and the rubber matrix by reducing the particle size. Meanwhile, the lattice distortion, defects, and amorphous crystals generated in the ultra-fine pulverization enhance the chemical reaction activity of the particles.

The particle size of starting samples and the coal gangue in the ground slurry was measured (Figure 4 and Table 3). The particles forming RCG had a diameter ranging between 0.3 and $20 \mu \mathrm{m}$ while the diameter of those forming ACG ranged between 0.4 and $100 \mu \mathrm{m}$. Additionally, the specific surface area of ACG was lower than RCG. The slightly larger size of ACG could be explained by the aggregation of fine particles [37] and the removal of fine particles after calcination. The organic components in coal gangue had lower hardness, making them easier to grind than inorganic minerals. Thus, the fine particle fraction was mainly organic components, and thermal activation removed them. Both ACG and RCG were refined after grinding, and the refinement rate of ACG was greater than that of RCG, revealing ACG was loose.

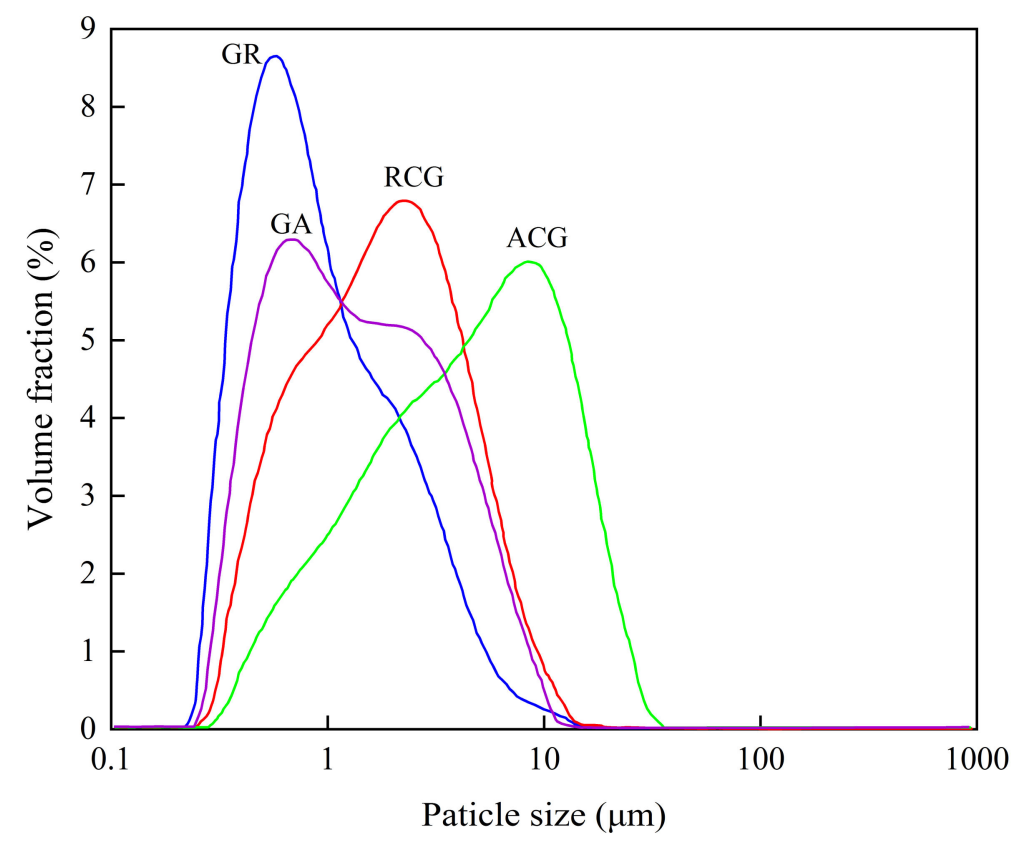

Figure 4. Particle size distribution of coal gangue before and after grinding. 
Table 3. Main particle size parameters and specific surface area of coal gangue before and after grinding.

\begin{tabular}{ccccc}
\hline Samples & $\mathbf{D}_{\mathbf{1 0}}(\boldsymbol{\mu m})$ & $\mathbf{D}_{\mathbf{5 0}}(\boldsymbol{\mu m})$ & $\mathbf{D}_{\mathbf{9 0}}(\boldsymbol{\mu m})$ & Specific Surface Area $^{\mathbf{1}}\left(\mathbf{m}^{\mathbf{2}} \cdot \mathbf{g}^{-\mathbf{1}}\right)$ \\
\hline RCG & 0.572 & 1.832 & 5.135 & 4.67 \\
GR & 0.384 & 0.822 & 2.938 & 8.12 \\
ACG & 0.970 & 4.814 & 14.569 & 2.42 \\
GA & 0.466 & 1.327 & 4.695 & 5.93 \\
\hline
\end{tabular}

${ }^{1}$ The specific surface area were determined by the laser particle size analyzer.

The narrower particle size distribution curve of GR documented a more concentrated particle size distribution. Whereas the curve of GA was wider and the area on the right side of the peak was larger than that on the left, which reflected that its particles varied in size and the coarse fraction accounted for a high content.

\subsubsection{Surface Properties of Fillers}

FTIR spectra of fillers are shown in Figure 5. The spectrum of GR exhibited the following typical bands for kaolinite: 3694 and $3651 \mathrm{~cm}^{-1}$ corresponding to stretching modes of two outer surface $\mathrm{O}-\mathrm{Hs}$, while $3620 \mathrm{~cm}^{-1}$ corresponding to the stretching mode of the inner $\mathrm{O}-\mathrm{H} ; 1116,1034,1011 \mathrm{~cm}^{-1}$ corresponding to the stretching vibration of Si-O; $914 \mathrm{~cm}^{-1}$ corresponding to bending of the inner Al-OH; 540, 471, and $432 \mathrm{~cm}^{-1}$ corresponding to $\mathrm{Si}-\mathrm{O}-\mathrm{Al}^{\mathrm{VI}}$ bending vibration, $\mathrm{Si}-\mathrm{O}-\mathrm{Si}$ bending deformation, and $\mathrm{Si}-\mathrm{O}$ bending vibrations, respectively [47]. The existence of quartz was confirmed by bands at 790,754 , and $694 \mathrm{~cm}^{-1}$, and these three bands associated with two types of the Si-O bond include $\mathrm{Si}$ with basal oxygen $\left(790 \mathrm{~cm}^{-1}\right)$ and $\mathrm{Si}$ with apical oxygen $\left(754\right.$ and $\left.694 \mathrm{~cm}^{-1}\right)$. This result is consistent with the analysis concerning the mineral composition of the coal gangue.

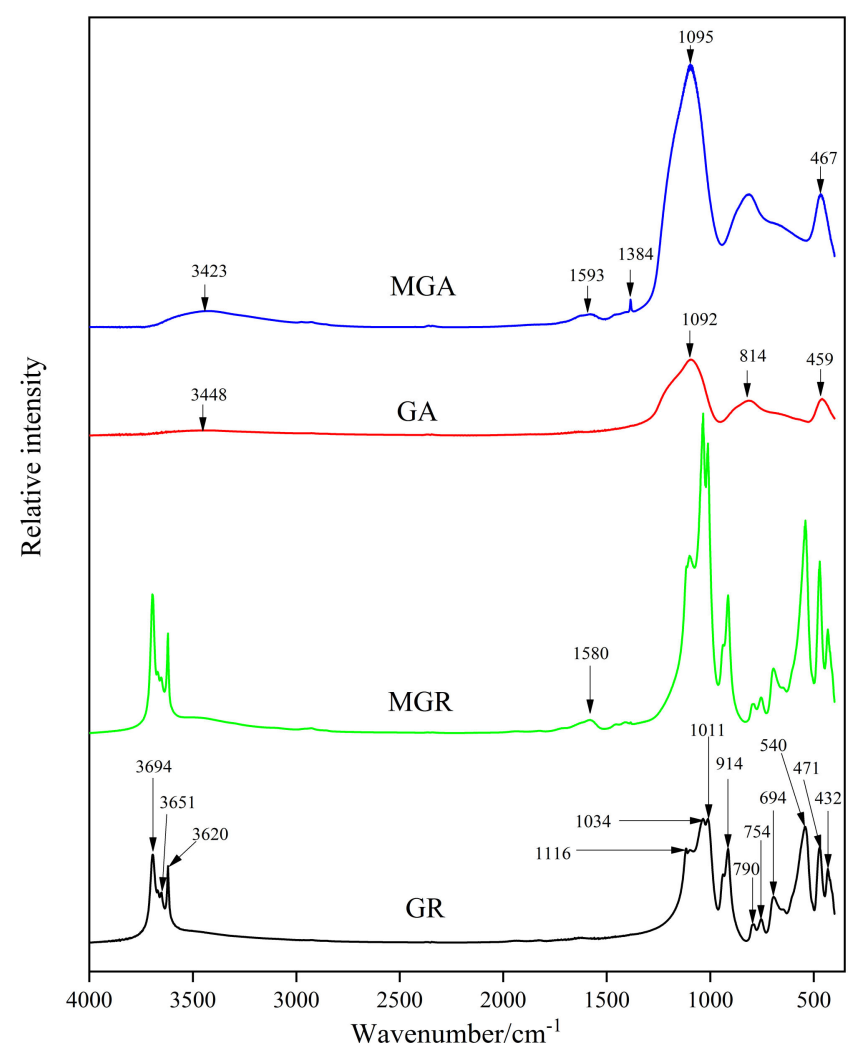

Figure 5. FTIR spectrum of different fillers. 
After thermal activation, the following changes in the spectrum of GA can be discriminated. The absence of bands at 3694, 3651,3620, and $914 \mathrm{~cm}^{-1}$ implied the disappearance of the O-H. Bands at 1116, 1034, and $1011 \mathrm{~cm}^{-1}$ disappeared and a new band at about $1092 \mathrm{~cm}^{-1}$ assigned to amorphous silica appeared which originated from Si-O-Si and $\mathrm{Al}^{\mathrm{IV}}-\mathrm{O}-\mathrm{Al}{ }^{\mathrm{VI}}$ linkages. Bands at 790,754 and $694 \mathrm{~cm}^{-1}$ vanished and a new broad band at about $814 \mathrm{~cm}^{-1}$ corresponding to $\mathrm{Al}^{\mathrm{IV}}-\mathrm{O}$ vibrations occurred [48]. Therefore, the coordination number of $\mathrm{Al}$ changed from six in kaolinite to four and five in metakaolinite [47]. In addition, the disappearance of $\mathrm{Al}-\mathrm{O}-\mathrm{Si}$ bending vibration at $540 \mathrm{~cm}^{-1}$ revealed that the octahedral structure of Al transformed into tetrahedral and pentahedral in metakaolinite [41]. Bands at 471 and $432 \mathrm{~cm}^{-1}$ vanished with the formation of a broad band at $459 \mathrm{~cm}^{-1}$ attributed to Si-O bond. Broad band at $3448 \mathrm{~cm}^{-1}$ demonstrated that the metakaolinite contained some residual $\mathrm{O}-\mathrm{Hs}$. This band would gradually become smaller as it is heated further, and eventually disappear before $980{ }^{\circ} \mathrm{C}$ [41].

The formation of hydrogen bonds between the modifier and the surface groups changed the force constants of the original chemical bonds. As a result, the relative strengths of the MGR and MGA bands increased compared to their unmodified counterparts, respectively. New broad bands, $1580 \mathrm{~cm}^{-1}$ for MGR and $1593 \mathrm{~cm}^{-1}$ for MGA were the characteristic bands of modifier. No band shift was observed in the spectrum of MGR, implying that the adsorption of modifier on the coal gangue surface was dominated by physical adsorption. While in the spectrum of MGA, the shifts from 1092 to $1095 \mathrm{~cm}^{-1}$, 459 to $467 \mathrm{~cm}^{-1}$ and 3448 to $3423 \mathrm{~cm}^{-1}$ indicated a changed chemical environment where the bonds were located. Furthermore, the appearance of new band at $1384 \mathrm{~cm}^{-1}$ in the spectrum of MGA made it credible that the modifier had been successfully immobilized on the surface of the coal gangue by chemical bonding.

The water contact angle $(\theta)$ images also reflected the changes in surface property for coal gangue. In general, the water contact angle can be used to evaluate the hydrophobicity of particles. The larger value of $\theta$ signifies the stronger the hydrophobicity of the particles and the better the compatibility of the particles with the rubber. GA became less hydrophobic and its $\theta$ decreased compared to GR since thermal activation removed the organic components. The $\theta$ of MGR was greater than GR and that of MGA was larger than GA as a result of surface organic by modifying (Figure 6). The modifier coated on the external surface of coal gangue improved the compatibility between filler and rubber matrix, thus reinforcing the mechanical properties of filled rubber composites [31].

\subsection{Characterization of Coal Gangue/SBR Composites}

\subsubsection{Optimum Curing Time of Coal Gangue/SBR Composites}

The $\mathrm{pH}$ of the filler significantly affects the vulcanization performance of the rubber compound. As shown in Figure 7a, both activation and modification decreased the $\mathrm{pH}$ of coal gangue. The lower $\mathrm{pH}$ of carbon black or inorganic filler corresponds to the longer curing time. The pH of MGA was lower than that of GR and GA, so the curing time of MGA-SBR was longer than that of GR-SBR and GA-SBR. After calcination, the kaolinite in raw coal gangue was transformed into highly reactive metakaolinite (Figures 1 and 5), so the activity of MGA was higher than that of MGR. The vulcanization process of MGASBR was delayed due to the adsorption of the highly reactive MGA on the curing agent. In addition, the organic and inorganic sulfur in coal gangue which served to shorten the curing time, were removed by calcination. As a result, MGA inherently contained less sulfur than MGR. High activity and low sulfur content leads to longer curing time of MGA-SBR than MGR-SBR. 


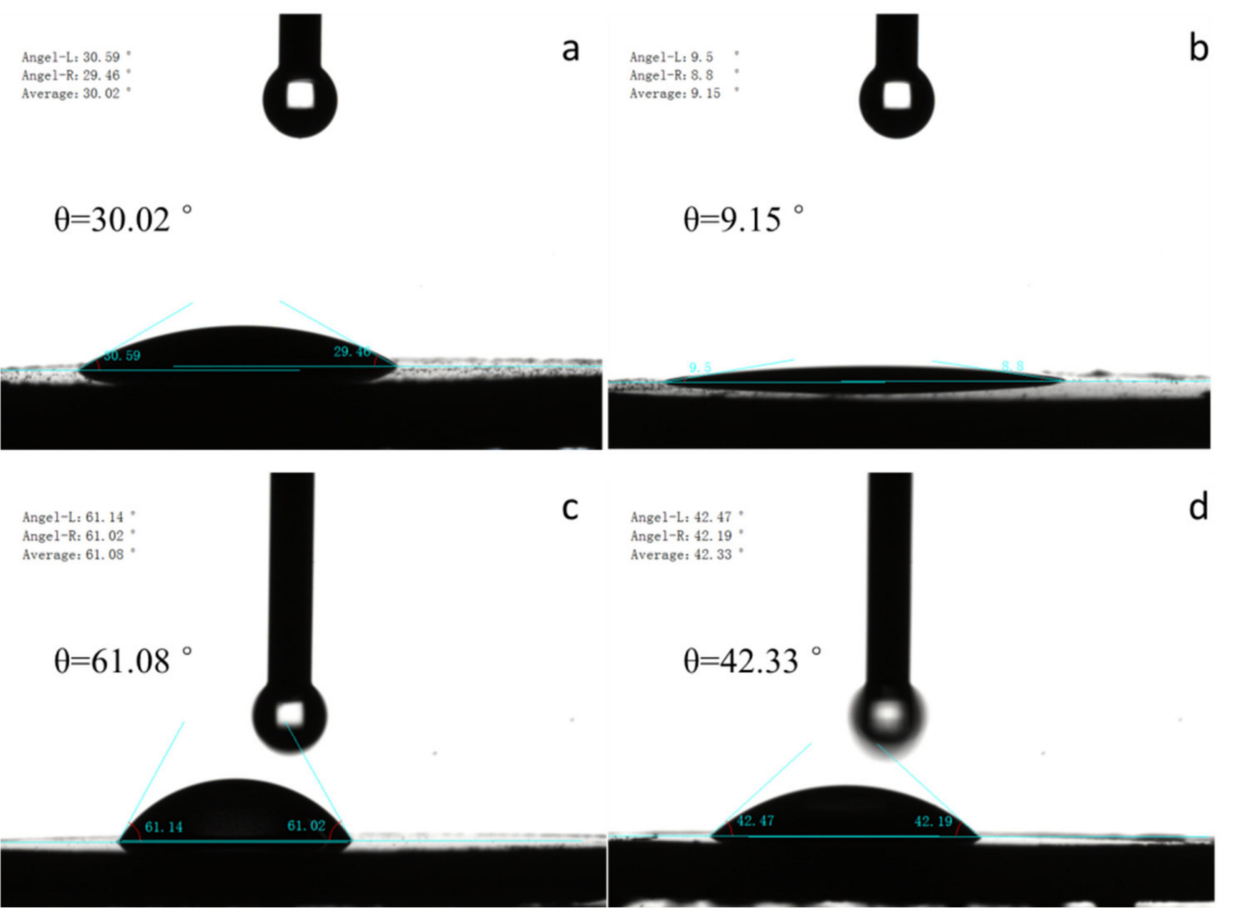

Figure 6. Water contact angle of different fillers: (a) GR, (b) GA, (c) MGR, (d) MGA.
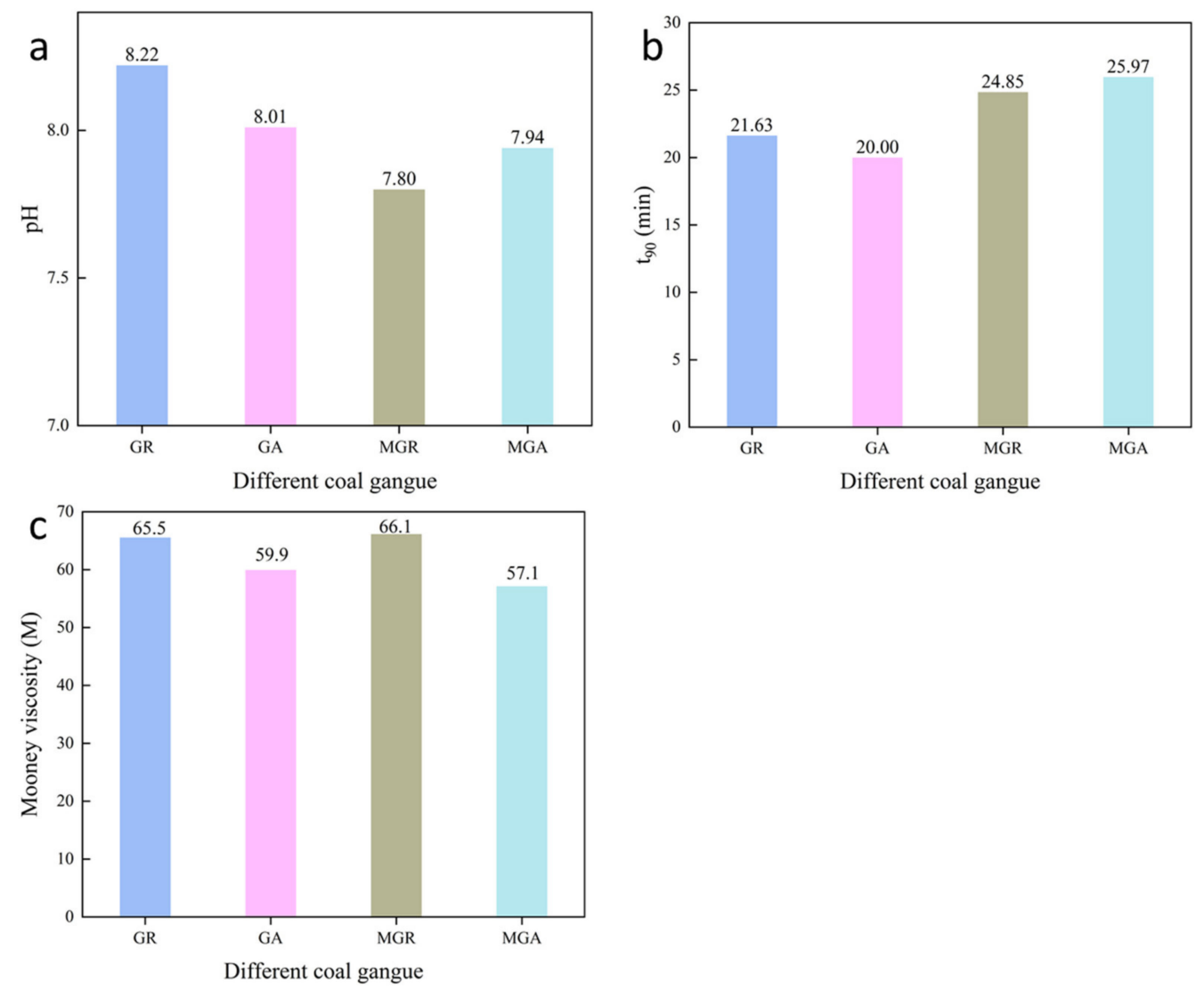

Figure 7. $\mathrm{pH}$ of coal gangue (a), t90 (b) and Mooney viscosity (c) of coal gangue/SBR composite.

The compound is difficult to mix evenly if the Mooney viscosity is too high. If the viscosity is properly reduced, the compound will have good fluidity and be easy to blend. As shown in Figure 7c, MGA reinforced rubber had the lowest Mooney viscosity than the other three composites, which was favorable for the superior dispersibility of the filler. 


\subsubsection{Dispersion of Coal Gangue in the Rubber Matrix}

GR presented as a large number of spherical agglomerates with a diameter of about $10-40 \mu \mathrm{m}$ in the rubber matrix as shown in Figure 8a. The formation of spherical agglomerates may be related to organics in GR and sulfur or sulfur bloom. Only few debris particles scattered in the rubber in Figure 8a". Large agglomerates were relatively difficult to participate in the cross-link reaction with rubber macromolecules. Thermal activation decreased the surface energy of the particles, thus reducing the particle-particle conjunction. In addition, the loose structure of coal gangue caused by thermal activation could also improve the dispersion of gangue [49]. Therefore, GA had fewer large agglomerates (Figure $8 \mathbf{b}$ ) and more debris in the matrix than GR (Figure $8 \mathbf{b}^{\prime \prime}$ ). Modification improved the dispersion of coal gangue by enhancing the compatibility between gangue and rubber. In Figure $8 c$, the coal gangue agglomerates in the matrix were less and smaller than that of GR. However, the debris of MGR clustered into smaller agglomerates rather dispersed in Figure $8 c^{\prime \prime}$. The brittle fracture surface of MGA-SBR was smooth without noticeable agglomerates (Figure $8 \mathrm{~d}, \mathrm{~d}^{\prime}$ ), which demonstrated that MGA only had smaller agglomerates in the matrix. MGA was most homogeneously dispersed in the polymer among the four kinds of fillers. Moreover, MGA bond much more tightly to rubber than the former three fillers with some particles even encapsulated by rubber (Figure 8d").
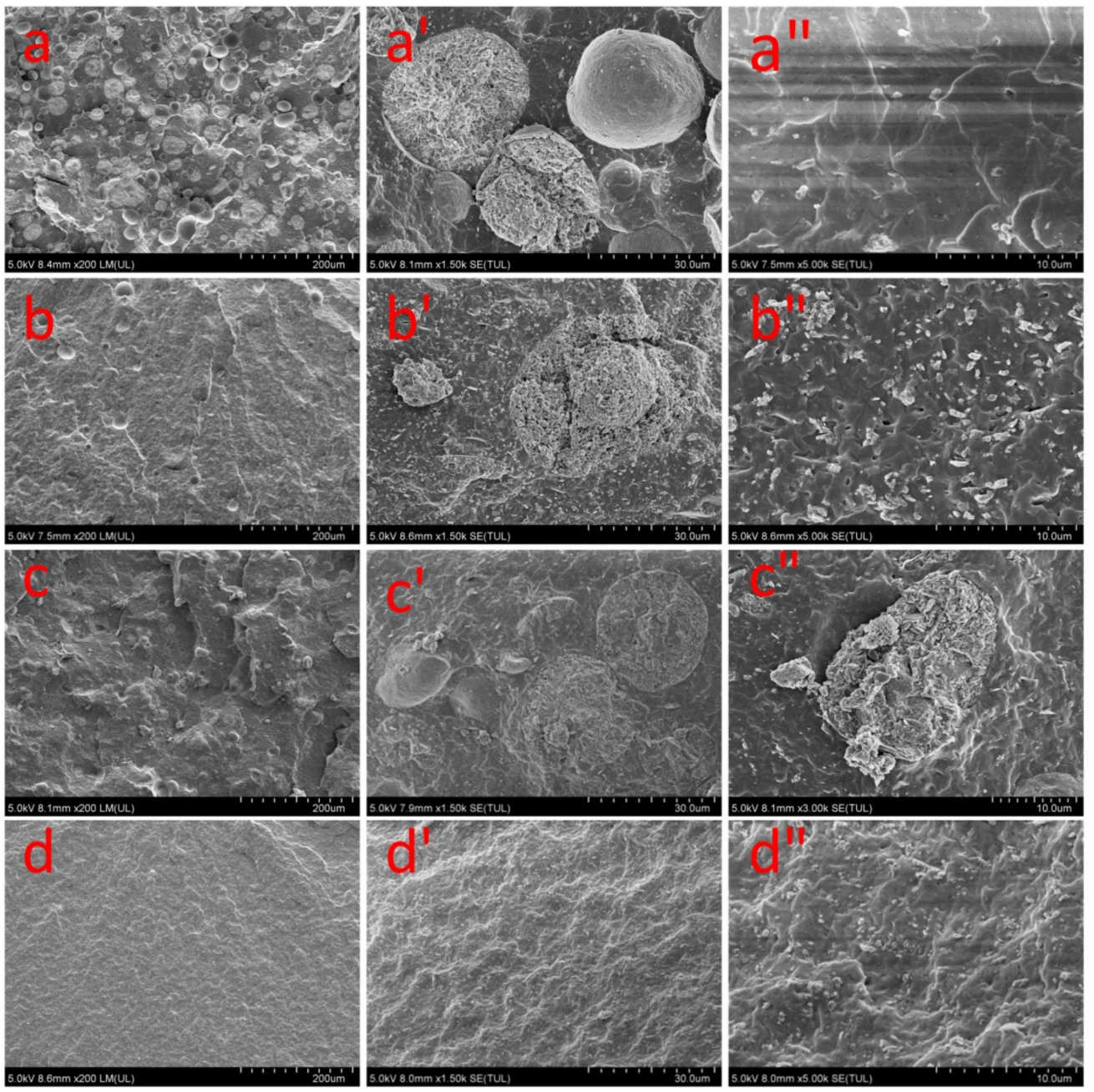

Figure 8. SEM observation of coal gangue/SBR composites: $\left(\mathbf{a}, \mathbf{a}^{\prime}, \mathbf{a}^{\prime \prime}\right)$ GR-SBR; $\left(\mathbf{b}, \mathbf{b}^{\prime}, \mathbf{b}^{\prime \prime}\right)$ GA-SBR; $\left(\mathbf{c}, \mathbf{c}^{\prime}, \mathrm{c}^{\prime \prime}\right)$ MGR-SBR; $\left(\mathbf{d}, \mathrm{d}^{\prime}, \mathrm{d}^{\prime \prime}\right)$ MGA-SBR.

The contact angle exhibited uncalcined fillers (GR, MGR) was more hydrophobic than that of calcinated fillers (GA, MGA). However, their dispersibility in rubber matrix 
was not as good as that of calcinated samples, probably due to the organic components induced the self-adhesion of the particles in the process of drying and blending with the rubber. The dispersibility of MGA in the rubber matrix was markedly improved by its loose structure, high volume pores, and effective bonding with modifier, and good fluidity of its blending rubber.

\subsubsection{Mechanical Properties of Coal Gangue/SBR Composites}

The $\mathrm{D}_{90}$ of GR is $2.938 \mu \mathrm{m}$ (Table 3), which means that the vast majority of the single particles are quite small and GR has the potential to enhance SBR. However, the fineparticles coalesced into massive spherical aggregates in the SBR matrix (Figure 8a,a'). These aggregates were not conducive to the adsorption of particles to rubber macromolecules and increased the dispersion distance between particles, thus creating weak links [50]. The aggregates separated from the polymer matrix when subjected to external forces. The separation caused cavitation effects and stress concentrations, resulting in cracks and damage to the polymer material. Therefore, GR had almost no reinforcing effect, and the mechanical properties GR-SBR were the worst (Table 4).

Table 4. Mechanical property of coal gangue/SBR composite.

\begin{tabular}{ccccccccc}
\hline Samples & $\begin{array}{c}\text { Shore A } \\
\text { Hardness }\left({ }^{\circ}\right)\end{array}$ & $\begin{array}{c}\text { Tensile Strength } \\
(\mathbf{M P a})\end{array}$ & $\begin{array}{c}\text { Elongation at } \\
\text { Break (\%) }\end{array}$ & & Modulus (MPa) & $\begin{array}{c}\text { Tear Resistance } \\
(\mathbf{k N / m})\end{array}$ \\
\hline & & & & $\mathbf{5 0 \%}$ & $\mathbf{1 0 0 \%}$ & $\mathbf{2 0 0 \%}$ & $\mathbf{3 0 0} \%$ \\
\hline GR & 51 & 1.54 & 380.18 & 0.73 & 0.85 & 1.02 & 1.27 & 12.67 \\
GA & 54 & 4.10 & 447.24 & 1.15 & 1.50 & 1.98 & 2.53 & 15.48 \\
MGR & 49 & 4.55 & 633.28 & 0.92 & 1.18 & 1.57 & 1.90 \\
MGA & 51 & 10.24 & 509.36 & 1.07 & 1.55 & 3.00 & 4.92 & 20.34 \\
\hline
\end{tabular}

The mechanical properties of GA-SBR and MGR-SBR were better because the weak points of GA and MGR in the rubber matrix decreased with the reduction in clusters. The modulus of GA-SBR were higher than that of MGR-SBR, implying that GA had a stronger restraining effect on rubber macromolecular chains and GA-SBR was better in resisting external deformation. However, the elongation at break $\left(E_{b}\right)$, tensile strength $\left(\delta_{\mathrm{s}}\right)$, and tear resistance $\left(\varepsilon_{\mathrm{s}}\right)$ of GA-SBR were smaller than that of MGR-SBR. Several reasons might exist for this opposite numerical relationship: (1) the bonding force between GA and rubber was strong within certain distance, once the deformation was too large, the interaction force drops rapidly and the rubber fractured; (2) the hydrophobic ends of modifier on the surface of MGR were chemically bonded or physically entangled with the rubber macromolecules, and the chains would be stretched and slip under stress. The stretches and slips effectively transferred the stress and alleviated the premature fracture of the composites caused by stress concentration, thus improving the $\mathrm{E}_{\mathrm{b}}$ of MGRSBR; (3) the orientation of molecular chains caused by stretches and slips increased the strength to resist deformation, so the $\delta_{\mathrm{S}}$ and $\varepsilon_{\mathrm{S}}$ of MGR-SBR were higher than those of GA-SBR.

MGA-SBR reached 6.6, 1.8, and 3.9 times the $\delta_{\mathrm{s}}, \varepsilon_{\mathrm{s}}$ and $300 \%$ modulus of GR-SBR, respectively. The best dispersion in the rubber matrix and the strongest interaction between particles and rubber macromolecules gave MGA the best reinforcement among the four fillers. (1) The organic components might induce the self-adhesion of the particles in rubber matrix. Thermal activation removed the organic matter and decreased the surface energy of the particles, thus reducing the particle-particle conjunction. Therefore, the dispersibility of MGA was better than GR and MGR. The contact angle of MGA was larger than that of GA (Figure 6), indicating that modification endowed MGA stronger hydrophobicity and better compatibility with rubber. The lowest Mooney viscosity of the MGA-SBR compared to the other three compounds (Figure 7) meant that MGA-SBR had better fluidity and was easy to blend, which was beneficial for the excellent dispersion of the MGA (2) Desorption 
of water, decarbonization, and dihydroxylation caused by thermal activation increased the pore space of coal gangue, as demonstrated by the OAN of RCG and ACG and Figure 3. The increased pore space gave MGA more contact sites with rubber than uncalcined gangue (GR, MGR). In addition, calcination converted the kaolinite in the coal gangue to more reactive metakaolinite. MGA and the modifier were chemically combined (Figure 5), so the modifier can firmly adhere MGA to the rubber substrate. Thus MGA binds more tightly to the rubber than the unmodified GA. MGR was physically bonded to the modifier as indicated by FTIR and thermogravimetric analysis, so the bonding strength of MGA to the rubber molecules was greater than that of MGR.

\subsubsection{Thermal Stability of Coal Gangue/SBR Composites}

The thermal data measured by thermogravimetric method including the temperature at which $5 \%$ mass loss occurs ( $T_{5}$, the onset temperature of decomposition), the temperature for $50 \%$ decomposition ( $T_{50}$, mid-point of decomposition), the peak mass loss rate $\left(\mathrm{R}_{\mathrm{p}}\right)$, the temperature corresponding to $\mathrm{R}_{\mathrm{p}}\left(\mathrm{T}_{\mathrm{p}}\right)$, and residual mass at $600{ }^{\circ} \mathrm{C}\left(\mathrm{M}_{\mathrm{r}}\right)$ are widely used to evaluate the thermal stability of rubber composites [23,30]. The TG and DTG curves of coal gangue reinforce SBR were shown in Figure 9.
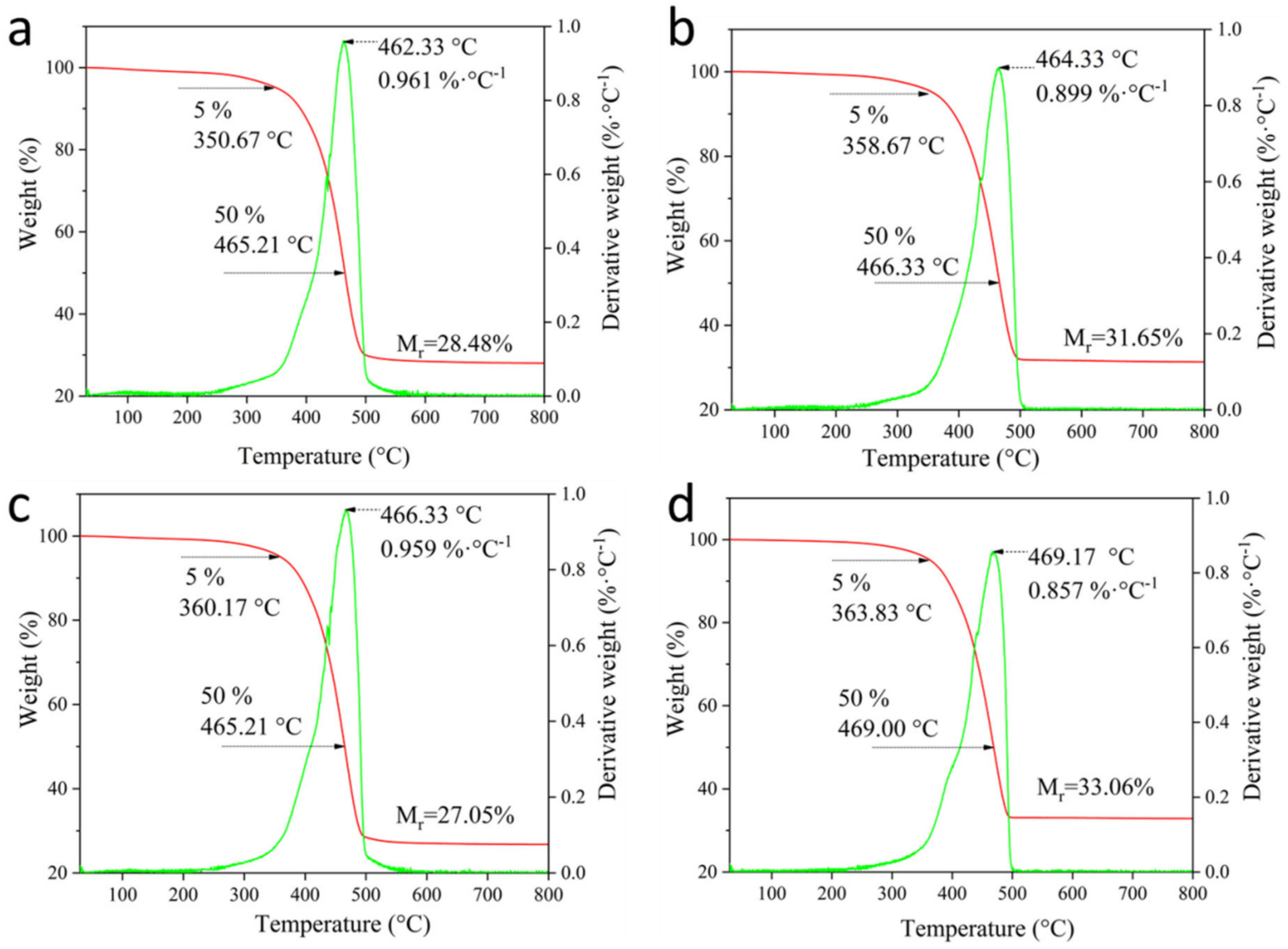

Figure 9. TG-DTG curves of coal gangue reinforced SBR: (a) GR-SBR; (b) GA-SBR; (c) MGR-SBR; (d) MGA-SBR.

The $T_{5}, T_{50}, T_{p}$ of GA-SBR, MGR-SBR, and MGA-SBR were larger than those of GRSBR. Among them, $\mathrm{T}_{5}$ increased most significantly. The $\mathrm{T}_{5}$ of former three vulcanizates were $358.67,360.17$, and $363.83{ }^{\circ} \mathrm{C}$ which were $8.00,9.50$, and $13.16^{\circ} \mathrm{C}$ higher, respectively, than that of the GR-SBR. The $\mathrm{R}_{\mathrm{p}}$ of the three composites had respective decreases of $6.45 \%$, $0.21 \%$, and $10.82 \%$ relative to that of GR-SBR. The increases of $\mathrm{M}_{\mathrm{r}}$ from GR-SBR to GA-SBR and MGR-SBR to MGA-SBR were due to the pre-removal of the decomposable components from the coal gangue by thermal activation. The modifier and MGR were combined by hydrogen bonding and physical adsorption (Figure 5). The modifier detached from the 
particles and became a decomposable component before $600{ }^{\circ} \mathrm{C}$, so the $\mathrm{M}_{\mathrm{r}}$ of MGR-SBR was $1.43 \%$ smaller than that of GR-SBR. The modifier was stable at high temperature by bonding with MGA through hydrogen bonding and chemical interaction (Figure 5). Simultaneously, MGA was more uniformly dispersed in rubber matrix than GA (Figure 8), so it had more active points to bond with rubber. In addition, MGA interacts strongly with rubber, leading to better restriction on the rubber macromolecules. Consequently, the $\mathrm{M}_{\mathrm{r}}$ of MGA filled rubber was greater than that of GA filled rubber.

Based on the discussion above, it could be concluded that the thermal stability of MGASBR was the best among the four compounds. (1) Thermal activation pre-removed the organic matter from coal gangue, and the residual inorganic material was not decomposable during the thermal analysis test. Therefore, calcined coal gangue (GA, MGA) was more effective in diluting the concentration of combustibles in composites than uncalcined coal gangue (GR, MGR) at the same dosage. Consequently, GA-SBR had better thermal stability than GR-SBR, and MGA-SBR was superior to MGR-SBR. (2) Modification improved the compatibility of particles with rubber (Figure 6), thus MGA was more uniformly dispersed in the rubber matrix than GA. As a result, MGA extended the heat flow diffusion path more, thereby reducing the heat flow. In addition, MGA was more tightly bound to the rubber through the modifier than MGR, because MGA was chemically bound to the modifier while MGR was physically bound to the modifier. The stronger interaction between MGA and rubber inhibited the escape of pyrolytic small molecules and the thermal movement of rubber molecular chains, eventually preventing the mass flow. So MGA-SBR had better thermal stability than MGR-SBR.

\section{Conclusions}

In this research, the basic properties of kaolinite-rich coal gangue and its thermal activated product including composition and structure, particle size distribution, and surface properties were studied. A series of coal gangue was compounded with SBR via melt blending method to investigate the effects of thermal activation and modification on the dispersibility of particles in rubber matrix and the mechanical and thermal properties of kaolinite-rich coal gangue reinforced SBR. The following conclusions can be drawn:

(1) The raw kaolinite-rich coal gangue aggregated into a large number of spherical clusters in the rubber matrix. However, coal gangue particles could achieve uniform dispersion by changing its composition, structure and surface properties through thermal activation and modification. MGA were more uniformly dispersed in the rubber matrix with preferable mobility of its blending compound, and more tightly bonded with the rubber than others fillers;

(2) The performance of GR-SBR was the worst, suggesting GR has no reinforcing effect on rubber. Although the performance of GA and MGR filled rubber were better, and MGA-SBR had the best reinforcement and thermal stability regardless its longer curing time. The tensile strength and tear strength of MGA reinforced rubber reached 6.6 times and 1.8 times of GR-SBR separately. Its $\mathrm{T}_{5}, \mathrm{~T}_{50}, \mathrm{M}_{\mathrm{r}}$ and $\mathrm{T}_{\mathrm{p}}$ increased by $13.16{ }^{\circ} \mathrm{C}, 3.79{ }^{\circ} \mathrm{C}$, $4.58 \%$, and $6.84{ }^{\circ} \mathrm{C}$, respectively, and $\mathrm{R}_{\mathrm{p}}$ decreased by $10.82 \%$, compared with GR filled rubber. The improvement of mechanical properties and thermal stability of coal gangue reinforced SBR was attributed to fine dispersion of particles in the rubber matrix besides the strong interactions between particles and rubber chains;

(3) With the melt blending method, the gangue did not reach the molecular level of dispersion and the kaolinite in coal gangue was not sufficiently exfoliated, so the lamellar structure did not contribute as much to the composite performance as the dispersion. The better dispersed mixing method is needed for the future studies. Furthermore, it is appropriate to optimize the formulation of the mixture, the vulcanization system and the dosage of the filler, as well as to combine the kaolinite-rich coal gangue with the reinforcing filler. 
Author Contributions: Conceptualization, Q.L. and K.Z.; writing—original draft preparation, K.Z.; writing—review and editing, Q.L. and L.L. (Lingsong Liu); Software, H.Z., Y.Y. and L.L. (Lihui Liu). All authors have read and agreed to the published version of the manuscript.

Funding: This research was funded by the National Key R\&D Program of China (No. 2019YFC1904903) and the Science and Technology Major Projects of Shanxi Province of China (No. 20181101003).

Acknowledgments: We are thankful to Zaozhuang Sanxing High-Tech Materials Company for providing equipment support.

Conflicts of Interest: The authors declare no conflict of interest.

\section{References}

1. Lu, Q.; Dong, X.; Zhu, Z.; Dong, Y. Environment-oriented low-cost porous mullite ceramic membrane supports fabricated from coal gangue and bauxite. J. Hazard. Mater. 2014, 273, 136-145. [CrossRef] [PubMed]

2. Li, D.; Wu, D.; Xu, F.; Lai, J.; Shao, L. Literature overview of Chinese research in the field of better coal utilization. J. Clean. Prod. 2018, 185, 959-980. [CrossRef]

3. Li, J.; Wang, J. Comprehensive utilization and environmental risks of coal gangue: A review. J. Clean. Prod. 2019, 239, 117946. [CrossRef]

4. Jablonska, B.; Kityk, A.V.; Busch, M.; Huber, P. The structural and surface properties of natural and modified coal gangue. J. Environ. Manag. 2017, 190, 80-90. [CrossRef]

5. Gong, G.; Xie, B.; Yang, M.; Yang, W.; Zhang, W.; Zhao, M. Mechanical properties and fracture behavior of injection and compression molded polypropylene/coal gangue powder composites with and without a polymeric coupling agent. Compos. Part A Appl. Sci. Manuf. 2007, 38, 1683-1693. [CrossRef]

6. Zhao, M.; Xiang, Y. Natural rubber vulcanizate reinforced by modified coal-shale-based fillers. J. Appl. Polym. Sci. 2004, 93, 1397-1400. [CrossRef]

7. Li, B.; Gong, G.; Xie, B.; Yang, W.; Yang, M.; Lai, S. Fracture behaviour of polypropylene sheets filled with epoxidized natural rubber (ENR)-treated coal gangue powder. J. Mater. Sci. 2007, 42, 3856-3864. [CrossRef]

8. Ye, T.; Min, X.; Li, X.; Zhang, S.; Gao, Y. Improved holding and releasing capacities of coal gangue toward phosphate through alkali-activation. Chemosphere 2021, 287, 132382. [CrossRef] [PubMed]

9. Li, Z.; Gao, Y.; Zhang, J.; Zhang, C.; Chen, J.; Liu, C. Effect of particle size and thermal activation on the coal gangue based geopolymer. Mater. Chem. Phys. 2021, 267, 124657. [CrossRef]

10. Li, C.; Wan, J.; Sun, H.; Li, L. Investigation on the activation of coal gangue by a new compound method. J. Hazard. Mater. 2010, 179, 515-520. [CrossRef]

11. Guan, X.; Chen, J.; Zhu, M.; Gao, J. Performance of microwave-activated coal gangue powder as auxiliary cementitious material. J. Mater. Res. Technol. 2021, 14, 2799-2811. [CrossRef]

12. Liu, L.; Zhang, H.; Algeo, T.J.; Zhang, K.; Hong, H.; Zhang, S.; Liu, Q. Control of coal-bearing claystone composition by sea level and redox conditions: An example from the Upper Paleozoic of the Datong Basin, North China. Appl. Clay Sci. 2021, $211,106204$. [CrossRef]

13. Cheng, H.; Liu, Q.; Yang, J.; Ma, S.; Frost, R.L. The thermal behavior of kaolinite intercalation complexes-A review. Thermochim. Acta 2012, 545, 1-13. [CrossRef]

14. Cheng, H.; Zhou, Y.; Liu, Q. Kaolinite Nanomaterials: Preparation, Properties and Functional Applications. In Nanomaterials from Clay Minerals; Wang, A., Wang, W., Eds.; Elsevier: Amsterdam, The Netherlands, 2019; p. 285.

15. Sánchez-Soto, P.J.; Jiménez de Haro, M.C.; Pérez-Maqueda, L.; Varona, I.; Pérez-Rodríguez, J.L. Effects of Dry Grinding on the Structural Changes of Kaolinite Powder. J. Am. Ceram. Soc. 2000, 83, 1649-1657. [CrossRef]

16. Stepkowska, E.T.; Perez-rodriguze, J.L.; de Haro, M.J.; Sánchez-Soto, P.J.; Maqueda, C. Effect of grinding and water vapour on the particle size of kaolinite and pyrophyllite. Clay Min. 2001, 36, 105-114. [CrossRef]

17. Yuan, S.; Li, Y.; Han, Y.; Gao, P. Effects of carbonaceous matter additives on kinetics, phase and structure evolution of coal-series kaolin during calcination. Appl. Clay Sci. 2018, 165, 124-134. [CrossRef]

18. Maia, A.Á.B.; Angélica, R.S.; de Freitas Neves, R.; Pöllmann, H.; Straub, C.; Saalwächter, K. Use of 29Si and 27Al MAS NMR to study thermal activation of kaolinites from Brazilian Amazon kaolin wastes. Appl. Clay Sci. 2014, 87, 189-196. [CrossRef]

19. He, Y.; Liu, L.; He, L.; Cui, X. Characterization of chemosynthetic $\mathrm{H}_{3} \mathrm{PO}_{4}-\mathrm{Al}_{2} \mathrm{O}_{3}-2 \mathrm{SiO}_{2}$ geopolymers. Ceram. Int. 2016, 42, 10908-10912. [CrossRef]

20. Liu, Q.; Zhang, Y.; Xu, H. Properties of vulcanized rubber nanocomposites filled with nanokaolin and precipitated silica. Appl. Clay Sci. 2008, 42, 232-237. [CrossRef]

21. Ptáček, P.; Frajkorová, F.; Šoukal, F.; Opravil, T. Kinetics and mechanism of three stages of thermal transformation of kaolinite to metakaolinite. Powder Technol. 2014, 264, 439-445. [CrossRef]

22. Chen, J.; Xu, K.; Rongkai, P.; Peng, G.; Ma, L.; Zheng, L. Effect of Activated and Modified Conditions on Properties of Coal Gangue Powder Reinforced Natural Rubber. Polym. Mater. Sci. Eng. 2013, 29, 59-62. Available online: https://en.cnki.com.cn/ Article_en/CJFDTotal-GFZC201308014.htm (accessed on 5 December 2021). [CrossRef] 
23. Zhang, Y.; Liu, Q.; Zhang, S.; Zhang, Y.; Zhang, Y.; Liang, P. Characterization of kaolinite/styrene butadiene rubber composite: Mechanical properties and thermal stability. Appl. Clay Sci. 2016, 124-125, 167-174. [CrossRef]

24. Yang, Y.; Zhang, H.; Zhang, K.; Liu, L.; Ji, L.; Liu, Q. Vulcanization, interfacial interaction, and dynamic mechanical properties of in-situ organic amino modified kaolinite/SBR nanocomposites based on latex compounding method. Appl. Clay Sci. 2020, 185, 105366. [CrossRef]

25. Zhang, Y.; Liu, Q.; Zhang, S.; Zhang, Y.; Cheng, H. Gas barrier properties and mechanism of kaolin/styrene-butadiene rubber nanocomposites. Appl. Clay Sci. 2015, 111, 37-43. [CrossRef]

26. Zhang, Y.; Liu, Q.; Zhang, Q.; Lu, Y. Gas barrier properties of natural rubber/kaolin composites prepared by melt blending. Appl. Clay Sci. 2010, 50, 255-259. [CrossRef]

27. Yahaya, L.E.; Adebowale, K.O.; Menon, A.R.R. Mechanical properties of organomodified kaolin/natural rubber vulcanizates. Appl. Clay Sci. 2009, 46, 283-288. [CrossRef]

28. Sukumar, R.; Menon, A.R.R. Organomodified kaolin as a reinforcing filler for natural rubber. J. Appl. Polym. Sci. 2008, 107, 3476-3483. [CrossRef]

29. Wu, W.; Tian, L. Formulation and morphology of kaolin-filled rubber composites. Appl. Clay Sci. 2013, 80-81, 93-97. [CrossRef]

30. Zhang, Y.; Liu, Q.; Xiang, J.; Frost, R.L. Thermal stability and decomposition kinetics of styrene-butadiene rubber nanocomposites filled with different particle sized kaolinites. Appl. Clay Sci. 2014, 95, 159-166. [CrossRef]

31. Qin, L.; Zhang, Y.; Zhang, Y.; Gong, Y. Efficient preparation of coal-series kaolinite intercalation compounds via a catalytic method and their reinforcement for styrene butadiene rubber composite. Appl. Clay Sci. 2021, 213, 106237. [CrossRef]

32. Xing, W.; Tang, M.; Wu, J.; Huang, G.; Li, H.; Lei, Z.; Fu, X.; Li, H. Multifunctional properties of graphene/rubber nanocomposites fabricated by a modified latex compounding method. Compos. Sci. Technol. 2014, 99, 67-74. [CrossRef]

33. Tang, K.; Wang, J. Chlorinated butyl rubber/two-step modified montmorillonite nanocomposites: Mechanical and damping properties. Chin. J. Chem. Eng. 2021, in press. [CrossRef]

34. He, S.; He, T.; Wang, J.; Wu, X.; Xue, Y.; Zhang, L.; Lin, J. A novel method to prepare acrylonitrile-butadiene rubber/clay nanocomposites by compounding with clay gel. Compos. B Eng. 2019, 167, 356-361. [CrossRef]

35. Sarkarat, M.; Lanagan, M.; Ghosh, D.; Lottes, A.; Budd, K.; Rajagopalan, R. High field dielectric properties of clay filled silicone rubber composites. Mater. Today Commun. 2020, 23, 100947. [CrossRef]

36. Dai, J.C.; Huang, J.T. Surface modification of clays and clay-rubber. Appl. Clay Sci. 1999, 15, 51-65. [CrossRef]

37. Derouiche, R.; Baklouti, S. Phosphoric acid based geopolymerization: Effect of the mechanochemical and the thermal activation of the kaolin. Ceram. Int. 2021, 47, 13446-13456. [CrossRef]

38. Zribi, M.; Samet, B.; Baklouti, S. Mechanical, microstructural and structural investigation of phosphate-based geopolymers with respect to P/Al molar ratio. J. Solid State Chem. 2020, 281, 121025. [CrossRef]

39. Medri, V.; Fabbri, S.; Dedecek, J.; Sobalik, Z.; Tvaruzkova, Z.; Vaccari, A. Role of the morphology and the dehydroxylation of metakaolins on geopolymerization. Appl. Clay Sci. 2010, 50, 538-545. [CrossRef]

40. Gharzouni, A.; Joussein, E.; Samet, B.; Baklouti, S.; Rossignol, S. Effect of the reactivity of alkaline solution and metakaolin on geopolymer formation. J. Non-Cryst Solids 2015, 410, 127-134. [CrossRef]

41. Chakraborty, A.K. Phase Transformation of Kaolinite Clay; Springer India: New Delhi, India, 2013; p. 87. [CrossRef]

42. Cheng, H.; Liu, Q.; Yang, J.; Frost, R.L. Thermogravimetric analysis of selected coal-bearing strata kaolinite. Thermochim. Acta 2010, 507-508, 84-90. [CrossRef]

43. Ptáček, P.; Šoukal, F.; Opravil, T.; Havlica, J.; Brandštetr, J. Crystallization of spinel phase from metakaoline: The nonisothermal thermodilatometric CRH study. Powder Technol. 2013, 243, 40-45. [CrossRef]

44. Ptáček, P.; Kubátová, D.; Havlica, J.; Brandštetr, J.; Šoukal, F.; Opravil, T. Isothermal kinetic analysis of the thermal decomposition of kaolinite: The thermogravimetric study. Thermochim. Acta 2010, 501, 24-29. [CrossRef]

45. Ptáček, P.; Opravil, T.; Šoukal, F.; Wasserbauer, J.; Másilko, J.; Baráček, J. The influence of structure order on the kinetics of dehydroxylation of kaolinite. J. Eur. Ceram. Soc. 2013, 33, 2793-2799. [CrossRef]

46. Yan, K.; Guo, Y.; Fang, L.; Cui, L.; Cheng, F.; Li, T. Decomposition and phase transformation mechanism of kaolinite calcined with sodium carbonate. Appl. Clay Sci. 2017, 147, 90-96. [CrossRef]

47. Ilić, B.; Radonjanin, V.; Malešev, M.; Zdujić, M.; Mitrović, A. Effects of mechanical and thermal activation on pozzolanic activity of kaolin containing mica. Appl. Clay Sci. 2016, 123, 173-181. [CrossRef]

48. Xing, H.; Liu, H.; Zhang, X.; Deng, H.; Hu, H.; Yao, H. Enhanced sodium adsorption capacity of kaolinite using a combined method of thermal pre-activation and intercalation-exfoliation: Alleviating the problems of slagging and fouling during the combustion of Zhundong coal. Fuel 2019, 239, 312-319. [CrossRef]

49. Liu, S.; Xiaowei, Z.; Zhou, H. Surface modification and application of kaolin filler. Conserv. Util. Min. Resour. $2010,1,24-29$.

50. Zhang, L. Rubber Nanocomposites: Fundamentals and Apllications, 1st ed.; Chemical Industry Press: Beijing, China, $2018 ;$ p. 92. 